Submission ID: 43854

\title{
Conceptual Geological Modeling of Achimov Layers in Terms of Severo-
} Samburgskoye Field

D.O. Mishina* (Gazpromneft NTC), K.A. Bogdanova (Gazpromneft NTC)

\section{SUMMARY}

This work includes investigation of all information and from this creation of two different geological scenarios for achimov layer of Severo-Samburgskoye field, that take into account all field uncertainty. First of all it includes inspection of core and detection of facies with typical reservoir characteristics. Than core information is transferred into well without core recovery using well survey data. Also we performed seismic interpretation and choose such attribute that allow to contour facies distribution on space. After that we distinguish well test results and recognize that they illustrate different results, so decision was taken to create two different geological scenarios,. First of which includes one united reservoir with assumption that results of well test are incorrect, the second variant of geological scenarios includes three reservoirs that disconnected with each other and have it their own oil water contact. Than we estimates optimal development strategy for each variants and understand that for further decisions it Is necessary to implement additional exploration program which allow to reduce risks and as consequence to increase economic efficiency. 
Концептуальное геологическое моделирование ачимовских отложений на примере Северо-Самбургского месторождения

Д. О. Мишина* (ООО «Газпромнефть НТЦ»), К.А. Богданова (ООО «Газпромнефть НТЦ»)

\section{Введение}

Объектом данной работы являются ачимовские пласты Северо-Самбургского месторождения, которые на данный момент относятся к одним из наиболее перспективных объектов для разработки. Изучаемые отложения ачимовских толщ накапливались в глубоководных морских условиях преимущественно в виде конусов выноса, которые представлены плохосортированным материалом, часто переслаиванием песчаных и глинистых разностей, и имеют сильную фациальную дифференциацию по площади. Для ачимовских пластов характерны большие неопределённости в оконтуривании залежей и определении их гидродинамической связности, характеристике фильтрационно-емкостных свойств.

Для принятия лучших проектных решений необходимо четкое описание геологии изучаемого объекта, которое включает понимание о форме и положении песчаных тел в пространстве, закономерностях распространения ФЕС в зависимости от фациальной принадлежности осадков. Геологическая характеристика и особенности строения резервуара отражаются в концептуальных геологических моделях. В компании Газпромнефть НТЦ широко используется применение концептуальных геологических моделей на любом этапе изучения объекта, что позволяет более достоверно прогнозировать наличие и качество коллектора, что напрямую влияет на достоверность оценки месторождения, успех реализации программы ГРР и подтверждаемость показателей разработки.

В данной работе представлен пример создания нескольких альтернативных концептуальных геологических моделей ачимовских отложений, оценка их неопределенностей, вариантов разработки и успешности их реализации. В итоге по результатам оценки предлагается программа доравзедки, которая может снять существующие неопределенности.

\section{Создание базовой концептуальной геологической модели}

Создание концептуальной геологической модели включает в себя сбор и изучение всей имеющейся информации о месторождении, создание седиментационной модели, петрофизической модели, сейсмофациальной модели, которые в дальнейшем объединяются в 3D геологическую модель месторождения.

Сбор исходной информации

В пределах Северо-Самбургского месторождения пробурено 7 скважин, в которых проведен стандартный комплекс ГИС и испытания. В во всех скважинах был отобран керн, однако результаты петрофизических исследований есть только в четырех скважинах, в пяти скважинах присутствует керновой материал, пригодный для литологического описания. Почти вся площадь покрыта сейсмикой $3 \mathrm{D}$, качество которой оценивается как низкое.

Для создания седиментационной модели было произведено макроскопическое описание керна в пяти скважинах, по его итогам с учетом выделенных типичных последовательностей смены текстурно-структурных особенностей в керне производилась интерпретация фаций и определение условий осадконакопления. Отложения накапливались в глубоководноморских условиях в виде конусов выноса и представлены следующими фациями:

- Депоцентр (верхняя часть конуса выноса) - мощные массивные пески, преимущественно крупнозернистые, вытянутые в направлении поступления осадка;

- Лопасть (средняя часть конуса выноса) - более расчлененные песчаные тела 
- Дистальная часть (нижняя часть конуса выноса) - наиболее мелкозернистые и глинистые отложения с высокой степенью расчлененности.

Данные керна в дальнейшем увязывались с каротажными кривыми для трансляции выделенных фаций на другие скважины, где нет выноса керна.

Создание петрофизической модели помимо интерпретации ГИС, которая включает в себя выделение коллекторов, определение пористости, проницаемости и насыщенности, включает в себя анализ петрофизической зависимости Кп-Кпр. На рис. 1 представлен график зависимости Кп-Кпр с дифференциацией по фациям, фация дистальной части конуса характеризуется широким облаком с низкими значениями пористости и значениями проницаемости, как правило, ниже граничного 0,16 мД. Также по графику видно, что хотя облака значений, соответствующих лопасти и депоцентру, перекрываются, однако их можно поделить на два, и для каждой фации характерны свои диапазоны значений петрофизических свойств. Эта информация позволяет более точно распределять свойства в пространстве с учетом фаций.



Рисунок 1 Петрофизическая зависимость Кn-Кпр с дифференщичачией по фациям

Создание сейсмофациальной модели включает в себя структурные построения и динамический анализ атрибутов и с целью выявления их связи с выделенными фациями и распространением их по площади. По результатам комплексирования седиментационной, петрофизической и сейсмофациальной модели была создана геологическая модель, в которой изучаемый объект представляет собой единую залежь, сформированную в отложениях конуса выноса (рис. 2). 


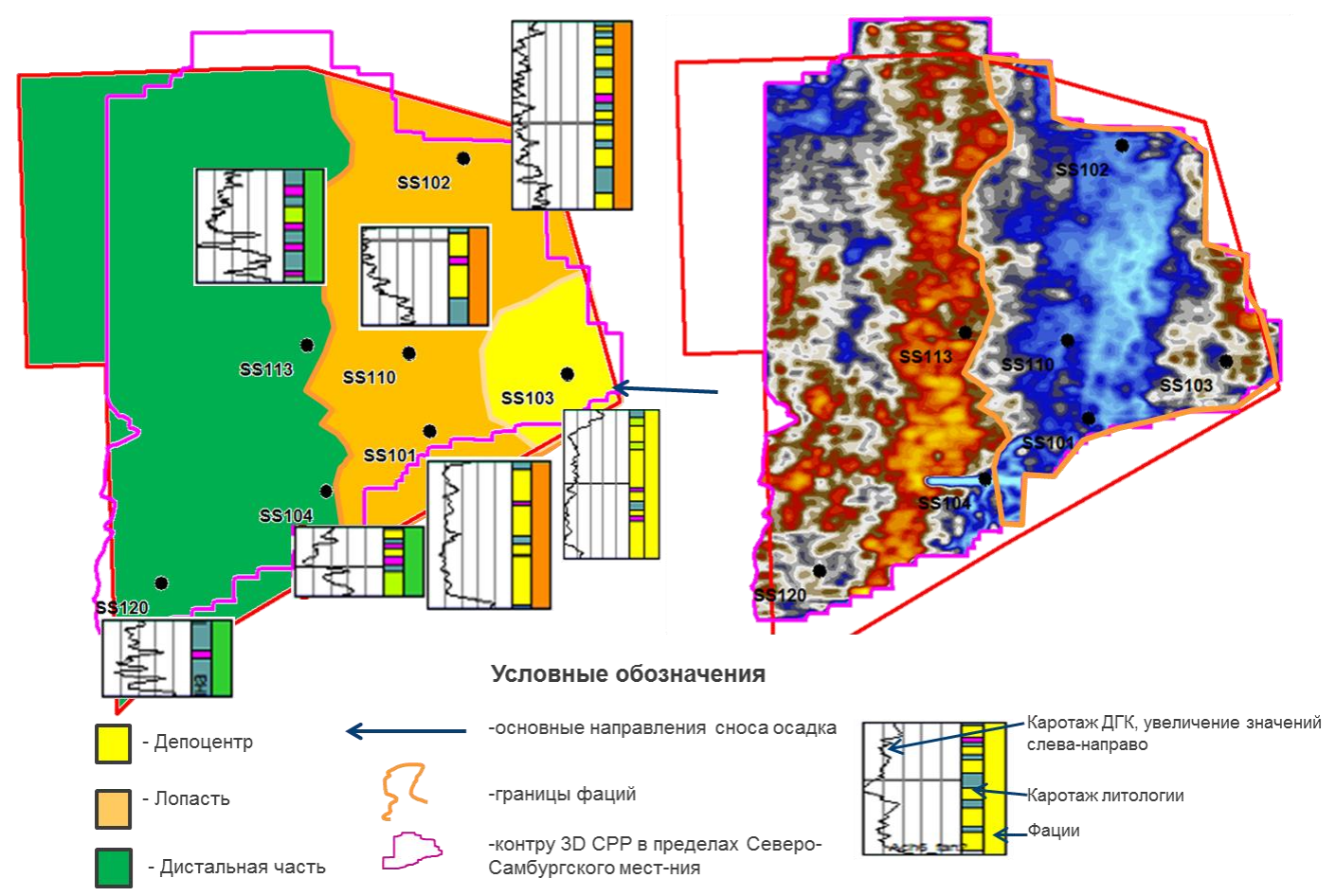

Рисунок 2 Конщептуальная фаџиальная карта пласта Ач5-1 (слева) и сейсмический атрибут (справа)

\section{Создание альтернативной модели}

Однако анализ результатов испытаний показал, что данные не согласуются между собой, все скважины должны находиться в отдельных линзах, главная неопределенность изучаемого объекта - наличие гидродинамически изолированных линз. Для оценки влияния этой неопределенности на проектные решения было принято решение о создании второй альтернативной концептуальной геологической модели. Дополнительно были изучены результаты анализа прогнозных крат и произведен детальный анализ сейсмических разрезов, которые подтвердили вероятность существования нескольких линз, относящихся к разным конусам выноса. По сценарию второй модели месторождение включает 3 залежи с разными контактами, сформированные разными конусами выноса, отложения которых между собой гидродинамически не связаны (рис. 3).

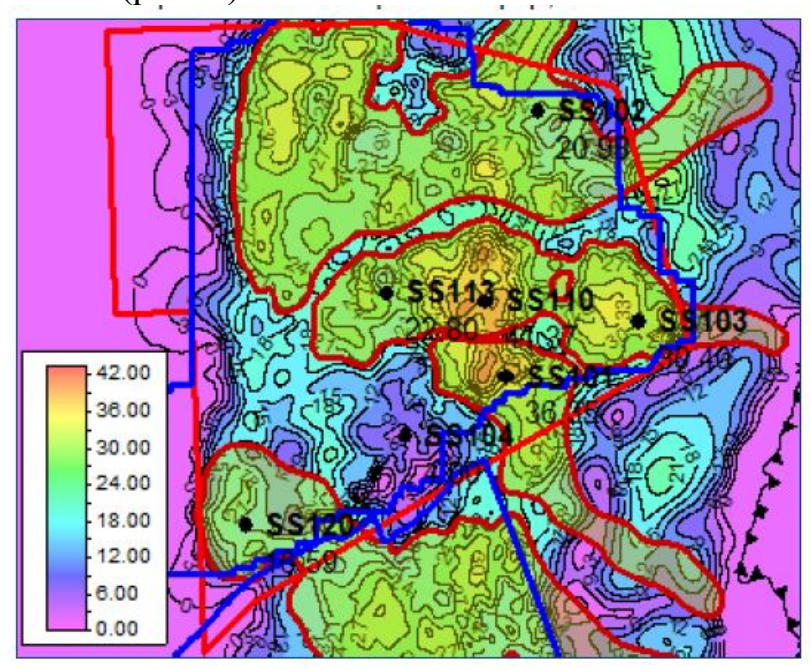

Рисунок 3 Прогнозная карта эффективных толщин пласта Ач5-1 с альтернативным распределением конусов выноса 


\section{Анализ результатов}

Для каждого геологического сценария был произведен подсчет запасов и определена оптимальная система разработки. В таблице1 представлены выборные параметры для каждого сценария. Анализ профилей добычи показал (рис. 4), что альтернативный геологический сценарий экономически не рентабелен.

Таблица 1 Параметры вариантов разработки для двух вариантов геологических сценариев

\begin{tabular}{|l|l|}
\hline \multicolumn{1}{|c|}{ Базовая геологическая модель } & \multicolumn{1}{|c|}{ Альтернативная геологическая модель } \\
\hline $\begin{array}{l}\text { Единая залежь (с допущениями по } \\
\text { испытаниям) }\end{array}$ & $\begin{array}{l}\text { Выделение трех залежей с разными } \\
\text { контактами }\end{array}$ \\
\hline Геологические запасы 79 млн т & Геологические запасы 26 млн т \\
\hline Технология бурения скважин-ГС с ГРП & Технология бурения скважин-ГС с ГРП \\
\hline Оптимальная ПСС -75 га/скв & Оптимальная ПСС - 100 га/скв \\
\hline Фонд -73 скв. & Фонд - 12 скв., из них 8 нерентабельных \\
\hline
\end{tabular}

Таким образом, для принятия дальнейших решений остро встает вопрос выбора правильной геологической концепции. В первом случае под сомнение попадают результаты испытаний, для снятия этой неопределенности планируется переиспытание скважины с целью подтверждения/опровержения характера насыщения и уровня ВНК. Для снятия неопределенностей распределения конусов выноса в объеме и гидродинамической связности залежи в программу доразведки также включает отстрел высокоплотностной сейсмики.

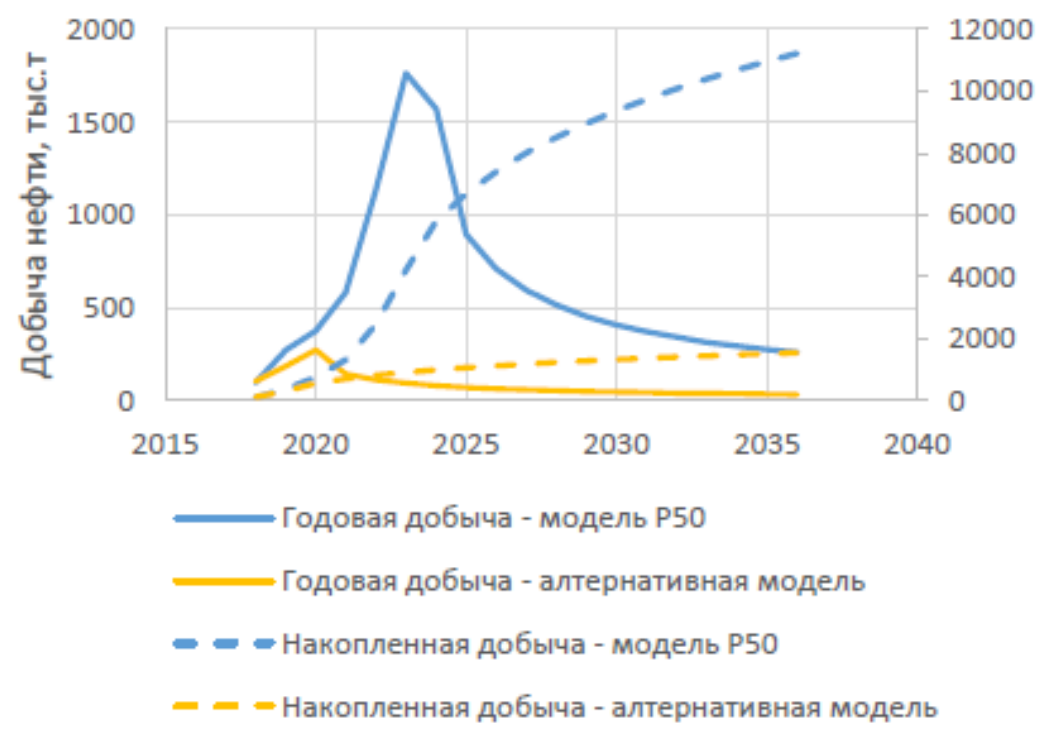

Рисунок 4 Сравнение профилей добычи для двух вариантов геологических сиенариев

Bblвodbl

Создание концептуальной геологической модели, включающее выделение особенностей условий осадконакопления и распределения осадков по площади, позволяет более точно оценить неопределенности, которые могут повлиять на принятие проектных решений и оценку рентабельности разработки месторождения в целом, и разработать оптимальную программу доразведки, позволяющую уменьшить неопределнности и повысить вероятность успеха. 